\title{
Research on the evaluation method of bearing capacity of existing Bridges based on dynamic load test
}

\author{
Qingcheng Yang ${ }^{1}$, Yufeng Ning ${ }^{2}$ and Weiwei Sun ${ }^{*}$, Shunchao Cheng ${ }^{2 *}$ \\ ${ }^{1}$ College of Civil Engineering, Southwest Forestry University, Kunming, Yunnan, 650224, China \\ ${ }^{2}$ College of Civil Engineering, Southwest Forestry University, Kunming, Yunnan, 650224, China
}

\begin{abstract}
The author carried out dynamic load test research on a prestressed concrete rigid frame bridge. Under dynamic load, the ratios of the measured and theoretical frequencies of the first four vertical vibrations of the bridge were $1.081,1.153$ respectively. The corresponding measured damping ratios are $0.011,0.010$ respectively. The maximum dynamic coefficient of bridge sports car test is 1.049 , and the corresponding dynamic strain increment coefficient is 0.059 . The measured impact coefficient is between 0.012 and 0.049 , which is basically equivalent to the design impact coefficient of 0.05 . The test results show that the existing bridge works well under the test load, and the bearing capacity of the structure meets the requirements of the design load level.
\end{abstract}

\section{Introduction}

In recent years, with the development of China's economy, the transportation industry also continues to flourish, building a large number of various Bridges, becoming the second largest bridge country after the United States. With the passage of time, many Bridges are faced with varying degrees of use hazard in terms of safety and durability. Therefore, through the bridge detection, technical analysis and technical condition assessment, the most real existing bridge operation status can be obtained.

Bridge dynamic load test is the purpose of the determination of bridge structure dynamic characteristics and the forced vibration response under dynamic load, the bridge structure of the natural vibration frequency, vibration mode, damping ratio and other modal parameters and dynamic displacement and dynamic stress of the structure of the bridge, impact coefficient, etc., and on the basis of dynamic load test, through the theoretical analysis and understand the real working state of the bridge structure, judging and evaluating the bearing capacity of bridge structure and conditions of use.

\section{Engineering overview}

In this paper, a national highway bridge in Yunnan province is used as the engineering support. The bridge is located in the grand Canyon area with steep terrain and adopts a three-span prestressed continuous rigid frame system. The specific span layout is $67.5 \mathrm{~m}+123.0 \mathrm{~m}+67.5 \mathrm{~m}=258.0 \mathrm{~m}$. The height of the bottom beam of the box girder is $7.30 \mathrm{~m}$, the height of the middle beam is $3.00 \mathrm{~m}$, and the thickness of the web is changed by three standard gradients of $0.50 \mathrm{~m}, 0.75 \mathrm{~m}$ and $1.30 \mathrm{~m}$. The thickness of the bottom plate varies from $0.30 \mathrm{~m}$ at the root to $0.854 \mathrm{~m}$ at the end according to 1.8 times parabola.

The main pier body adopts double-column thin wall pier body, the external outline of the pier body is rectangular, C40 concrete casting. The width of pier transverse bridge is the same as the width of main girder box bottom, which is $6.50 \mathrm{~m}$, the width of pier along the bridge is $1.20 \mathrm{~m}$, of which the pier height is $18.0 \mathrm{~m}$. Bored pile foundation is adopted for foundation, U-shaped abutment is adopted for abutment, and 6 bored piles with diameter of $2.00 \mathrm{~m}$ are set under it. The thickness of the cap is $3.5 \mathrm{~m}$, and the plane size of the cap is $8.20 \mathrm{~m} \times 13.20 \mathrm{~m}$. The highway grade of the bridge is second-class highway. Auto load for highway -I level.

Based on the current standard and theoretical calculation and analysis, this paper evaluates whether the bearing capacity of the test span of the bridge meets the design requirements. The vibration characteristics of the bridge span structure and the driving dynamic response of the test part are measured and the dynamic performance of the test bridge span structure is evaluated.

\section{Dynamic test}

\subsection{The content and method of the experiment}

The dynamic load test mainly includes two aspects: (1) The test of the natural vibration characteristics of the bridge structure, including the vertical second order vibration mode, natural frequency and damping ratio; (2) Bridge driving dynamic response test: Test the dynamic response of the test section under dynamic load, including dynamic strain, impact coefficient, damping ratio, etc. In the test, a vehicle with a load of about $400 \mathrm{kN}$ passes through the bridge at a constant speed of $10 \mathrm{~km} / \mathrm{h} \sim 40 \mathrm{~km} / \mathrm{h}$

\footnotetext{
* Corresponding author: $429459859 @$ qq.com
} 
to stimulate the bridge structure. The resistance of $120 \Omega$, sensitivity coefficient is 2.08 , standard with resistance strain gauge is $100 \mathrm{~mm}$ away match DH5908 dynamic signal test and analysis system for dynamic strain signal acquisition and processing.

\subsection{Dynamic response results processing and analysis}

The most unfavorable cross-section of the positive bending moment selected in the bridge is tested to strain. determine the dynamic strain of the bridge span structure under the action of running vehicle load, and the oscillation peak and valley value of the dynamic time curve at different vehicle speeds can be calculated to calculate the measured impact system. The design impact factor can be calculated by pressing: $\mu$

$$
\begin{aligned}
f< & 1.5 \mathrm{~Hz}, \quad \mu=0.05 \\
& 1.5 \mathrm{~Hz}<f<14 \mathrm{H}, \mu=0.1767 \ln f-0.0157 \\
f> & 14 \mathrm{~Hz}, \quad \mu=0.45
\end{aligned}
$$

In the equation: $f$-Structural base frequency $(\mathrm{Hz})$

According to the theory, the base frequency is calculated, and the calculated impact coefficient of the test bridge is 0.05 , the measured dynamic increment coefficient is shown in Table 1.

Table 1 The value of the impact coefficient at different speeds of the bridge

\begin{tabular}{|c|c|c|c|}
\hline $\begin{array}{c}\text { Test } \\
\text { Section }\end{array}$ & $\begin{array}{c}\text { Vehicle } \\
\text { Speed }\end{array}$ & $\begin{array}{c}\text { Maximum } \\
\text { dynamic } \\
\text { strain }(\boldsymbol{\mu \varepsilon})\end{array}$ & $\begin{array}{c}\text { Impact } \\
\text { factor } \\
(\mathbf{1}+\boldsymbol{\mu})\end{array}$ \\
\hline \multirow{2}{*}{$\begin{array}{c}\text { Cross- } \\
\text { mid- } \\
\text { section }\end{array}$} & $10 \mathrm{~km} / \mathrm{h}$ & 8 & 1.012 \\
\cline { 2 - 4 } & $20 \mathrm{~km} / \mathrm{h}$ & 9.5 & 1.019 \\
\cline { 2 - 4 } & $30 \mathrm{~km} / \mathrm{h}$ & 10 & 1.029 \\
\cline { 2 - 4 } & $40 \mathrm{~km} / \mathrm{h}$ & 12 & 1.049 \\
\hline
\end{tabular}

The measured results show that the maximum dynamic coefficient of the bridge sports car test is 1.049 , and the corresponding dynamic strain increment coefficient is 0.049 , which is less than the design impact coefficient (0.05). It should be noted that this dynamic load test adopts a single vehicle with low dynamic loading efficiency. In the actual multi-vehicle running of the bridge, the impact coefficient is generally lower than that of a single vehicle due to mutual cancellation. The measured impact coefficient during the test of the existing bridge sports car is lower than the design impact coefficient, indicating that the bridge deck is in good running condition.

\subsection{Analysis of the parameters of the power characteristics of the bridge}

For the long-span bridge structure, the pulsation method is usually used to determine the dynamic characteristics of the structure. The small and irregular vibration caused by various external factors is used to determine the dynamic characteristics of the structure. The Midas-Civil finite element structural analysis software is used for theoretical calculation of the dynamic characteristics of the bridge.

The vibration modal parameters of the bridge are obtained through the spectrum and phase analysis of the measured signals at each measuring point, as shown in Table 2.

Table 2 Measured values of vibration modal parameters

\begin{tabular}{|c|c|c|c|c|}
\hline order & $\begin{array}{c}\text { theory } \\
\text { frequency } \\
(\mathbf{H z})\end{array}$ & $\begin{array}{c}\text { measured } \\
\text { frequency } \\
(\mathbf{H z})\end{array}$ & $\begin{array}{c}\text { Measured } \\
\text { damping } \\
\text { ratio } \\
(\%)\end{array}$ & $\begin{array}{c}\text { Measured } \\
\text { frequency / } \\
\text { theoretical } \\
\text { frequency }\end{array}$ \\
\hline $1 \mathrm{st}$ & 1.423 & 1.538 & 0.011 & 1.081 \\
\hline $2 \mathrm{st}$ & 2.499 & 2.881 & 0.010 & 1.153 \\
\hline
\end{tabular}

According to the frequency domain analysis of the base frequency test, using finite meta-software calculation, the vibration pattern distribution map is shown in Figures 1 to 4 .

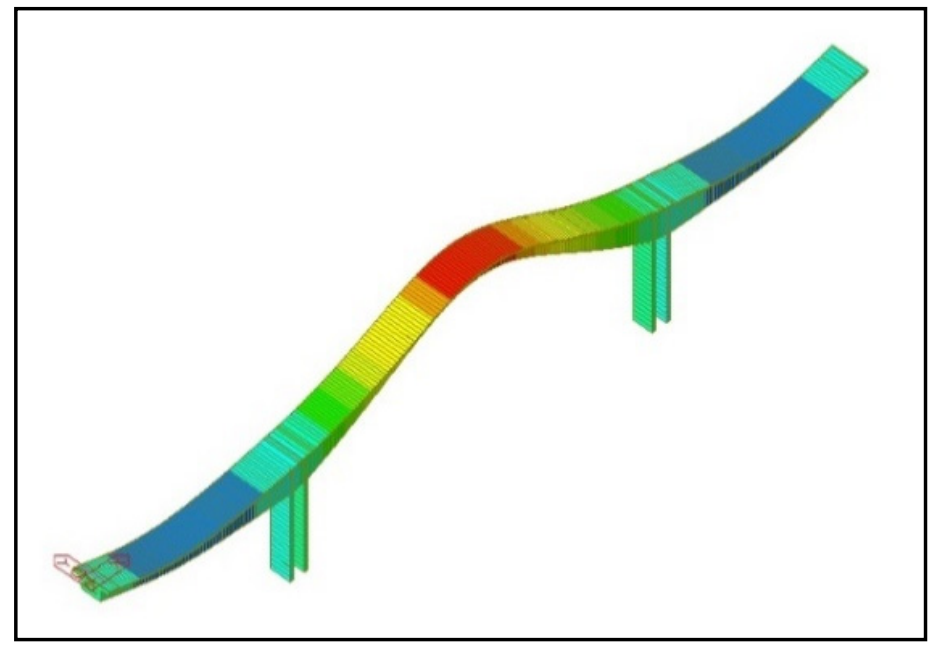

Figure 1. Theoretical mode of order-1 vertical bending 


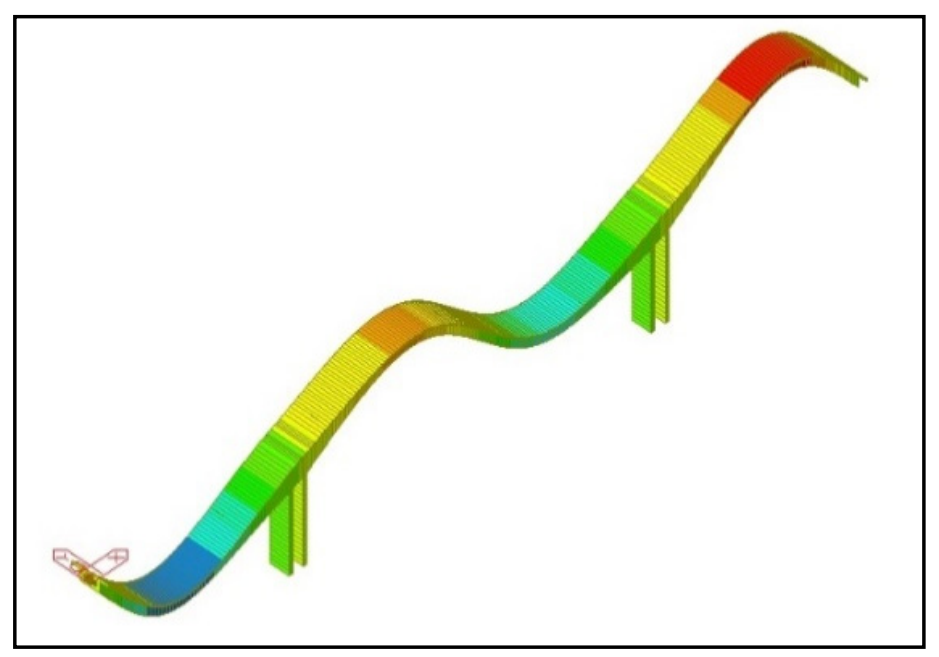

Figure 2. Theoretical mode of order-2 vertical bending

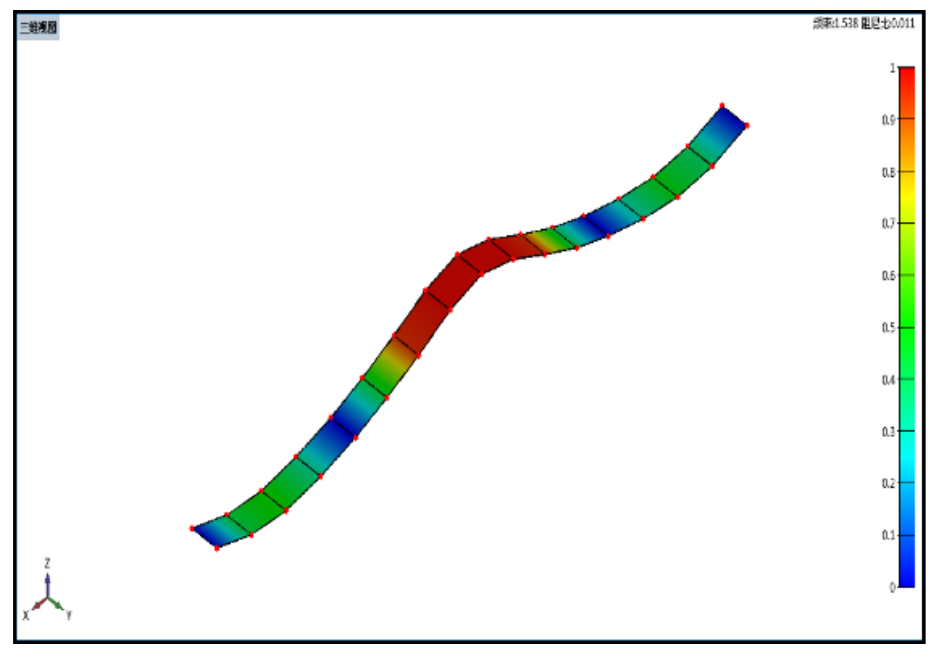

Figure 3. Measured vibration mode of order-1 vertical bending

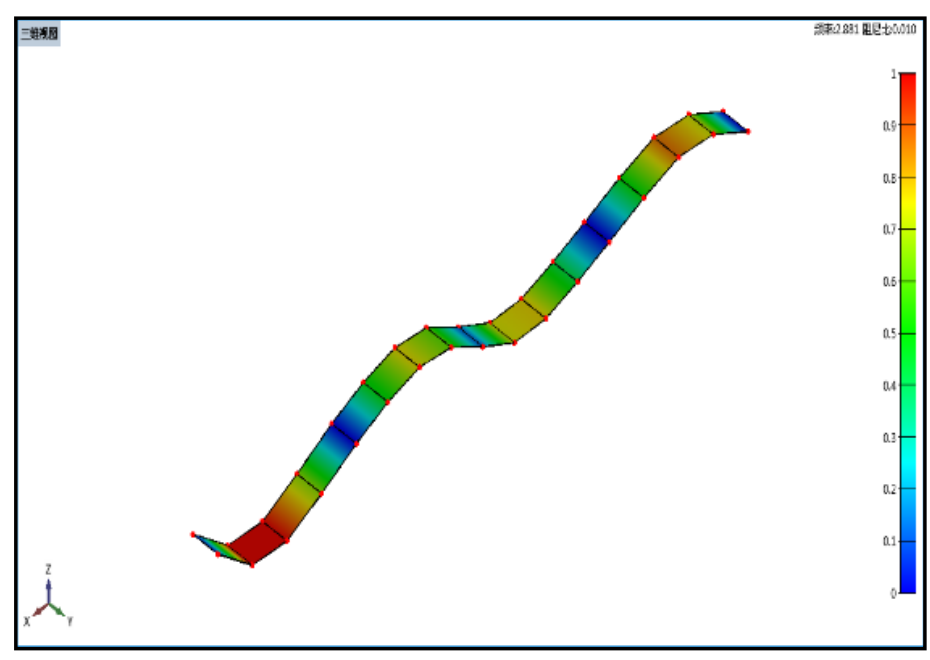

Figure 4. Measured vibration mode of order-2 vertical bending

From the measured modal parameters, it can be seen that the first order vibration of the bridge is mainly transverse vibration, which is consistent with the characteristics of higher pier and greater flexibility of the bridge. The vibration characteristics of the bridge structure are low frequency and small damping vibration, the value of which belongs to the normal range among similar bridge structures, and the overall stiffness of the bridge structure is normal. 


\section{Conclusion}

(1) The maximum dynamic coefficient of test at different speeds of the existing bridge is 1.049 , and the corresponding dynamic strain increment coefficient is 0.049 . The measured impact coefficient is between 0.012 and 0.049 , which is basically equivalent to the design impact coefficient (0.05).

(2) Since this dynamic load test uses a single vehicle, the dynamic loading efficiency is low. In the actual multivehicle operation of the bridge, the impact coefficient is generally less than that of a single vehicle, indicating that the bridge deck is in good running condition.

(3) The ratio of the measured frequency and the theoretical frequency of the two-order vibration of the existing bridge before vertical is 1.081 and 1.153 respectively, which meets the requirement that the ratio is greater than or equal to 0.90 in relevant regulations; The corresponding measured damping ratios are 0.011 and 0.010 respectively, which are within a reasonable range, indicating that the dynamic stiffness of the bridge meets the design and specification requirements.

\section{References}

1. Ministry of Transport, PRC, Highway and Bridge Carrying Capacity Test and Assessment Procedures: JTG/TJ21-2011[S].

2. Zhang Zhigang, XIAO Shengxie. Static and dynamic load test analysis of a three-span continuous beam bridge $[\mathrm{J}]$. Communications technology and economics, 16, 2014 (2):66-70.

3. Xiong Huizhong, LU Xin. Analysis of static and dynamic load test effect of continuous box Girder bridge [J]. Cryogenic Building Technology, 2012, 5:78-80.

4. Ministry of Transport, PRC, Load Test Rules for Highway and Bridge: JTG/T J21-01 -- 2015 [S].

5. Wang $\mathrm{z}$ b. application of force load test in bridge inspection and evaluation [J]. Journal of Qingdao university of science and technology,2007,28(1):1416.

6. Wang Gang, ZENG Jin, Quan Enmao. Test and Detection Technology of stress concrete continuous rigid frame bridge [J]. Communications technology and economy,2012,14(5):30-33.

7. Liu Hai. Dynamic Load Characteristics of beams [J]. Traffic World,2014,20:136-137. 